\title{
Local seismicity alterations in the South Yakutia mining region due to the technogenic impact on its geological environment
}

\author{
Nikolay Grib ${ }^{1,3^{*}}$, Valery Imaev ${ }^{1,2}$, Galina Grib ${ }^{1}$, Lyudmila Imaeva $^{2}$ and Igor Kolodeznikov ${ }^{3}$ \\ ${ }^{1}$ Technical Institute (Branch), Amosov North-Eastern Federal University, Neryungri, Russia. \\ ${ }^{2}$ Institute of the Earth's Crust, Siberian Branch, Russian Academy of Sciences, Irkutsk, Russia \\ ${ }^{3}$ Academy of Sciences of the Republic of Sakha (Yakutia), 677007, 33 Lenina, Yakutsk, Russia
}

\begin{abstract}
Impulse loads, arising due to the high natural seismicity of the South Yakutia region, exercise both direct and indirect effects on the upper part of the Earth's crust during industrial explosions. The direct effects result from nonlinear displacements caused by the blast wave and the subsequent formation of new disturbances. The indirect effects arise due to the activation of structural elements along geological contacts, leading to the emergence of technogenic seismicity foci. The foci of induced seismicity are either confined to the blast points, or located along the tectonic structures crossing quarry fields. The technogenic impact on the geological environment transforms the independent local seismic process, since explosions trigger a chain of local seismic events. The near-surface layers of the Earth's crust become activated in the area of dynamic influence of active faults. Under the influence of explosions, both the number of seismic events and the average level of released energy alter. Impulse loads on the geological environment lead to a spatial redistribution of the foci of low-energy $(K<7)$ earthquakes. The main form of the geodynamic development of seismogenic faults is the movement of their sides in the form of mutual "slippage". Seismic events are manifested only when the aforementioned form of deformation is impossible or difficult to develop, in other words, when the stress-state areas of the Earth's crust develop. Therefore, the shaking impact of blasts can be considered as a factor contributing to the predominance of aseismic forms of fault motion in the form of smooth slippage of their sides. In conclusion, the impact of industrial blasts can not only activate faults around the mining area, but also have an unloading effect on the foci of seismic hazard forming in the interior, i.e. the redistribution of earthquake energy in terms of reducing earthquake energy class.
\end{abstract}

\section{Introduction}

Long-term seismotectonic studies conducted in the south of Siberia, on the border of the Eurasian and Amur lithospheric plates, have established the formation of an independent

\footnotetext{
${ }^{*}$ Corresponding author: grib@nfygu.ru
} 
Olekmo-Stanovaya zone (OSZ), within which over 40,000 seismic events with a magnitude from $\mathrm{M} \geq 2.0$ to $\mathrm{M}=6.5-7.0$ were registered over the 60 -year-long period of instrumental observations [1]. In the present paper, we aim to analyse a site located in the central part of the OSZ in the vicinity of the Neryungri city, where various minerals are actively being mined.

The increasing scale and intensification of the Earth's interior exploration have revealed two major issues associated with the interaction between man and nature, i.e., the need to address problems involved with prevention of catastrophic emergency situations caused by technogenic seismicity and research into the possibility of active technogenic intervention into natural seismic processes.

The possibility of initiating earthquakes comes from a hypothesis that the Earth's interior is characterized by an unstable energy state. On its basis, a number of studies [2 - 5] have concluded that atomic explosions lead to a change in the seismic regime even at significantly large distances (thousands of kilometres) from the initiating impact.

An increase in the scale of human impact on the environment typically results in an increase in the load not only on such rapidly-responding ecosystem components as animals, plants, soil, water and air, but also on those its elements that are commonly considered to be unaffected by civilisation [6]. The latter, the most stable ecosystem components, were long believed to include the upper layers of the Earth's crust, as well as the deformation processes occurring therein [7]. It was conventional to refer diverse deformation processes of various space-time scales occurring in the Earth's crust, including earthquakes, anomalous deformations in fault zones, subsidence, landslides, mudflows, etc., exclusively to orogenic and adjacent areas. However, in recent years, the basic perceptions of the Earth's geodynamic state have radically changed. Long-term research carried out on geodynamic polygons has proven deformation processes to occur everywhere, even within ancient platforms and seismically quiet regions. These processes are manifested, e.g., as intense quasiperiodic vertical and horizontal movements along faults with amplitudes of up to $20-50 \mathrm{~mm} /$ year [8]. Published data indicates that earthquakes with a magnitude of $\mathrm{M}>7$ can occur even across most ancient platform areas [9, 10].

An increase in the scale of anthropogenic impact is known to intensify technogenic seismicity [11]. As a rule, the centres of technogenic earthquakes exhibit small depths, which fact amplifies their risk to the built environment. The small magnitudes of earthquakes are compensated by the proximity of their foci to the surface; as a result, a relatively weak technogenic earthquake is capable of causing local catastrophes [12]. In recent years, induced seismicity has become one of the problems associated with the geoenvironmental consequences of seismic effects from quarry blasts performed in mining regions [13 - 17].

In South Yakutia, the following types of human impact on nature capable of provoking earthquakes can be distinguished: the construction of a water reservoir, open mining operations in the Neryungrinsky coal mine and underground mining operations in other coal mines. Due to the high natural seismicity and proximity of the industrial zone to the city of Neryungri, these forms of anthropogenic impact can significantly affect the level of seismic and geo-environmental risks. The practical significance of solving these problems is extremely high for the economic development of the South Yakutia region [18].

\section{Experimental study}

The seismological monitoring data obtained for the period from January 1, 2002 to July 31 , 2012 was analysed with the purpose of assessing the level of technogenic seismicity in South Yakutia. The comparison of the seismological data with the volume of the rock mass blasted during this period produced the following regularity: an increase in the volume of 
blasted rock mass leads to an increase in the number of nearby earthquakes. The analysis was carried out applying a summarization approach, i.e., the total volume of the rock mass blasted during a month was compared with the number of nearby earthquakes having occurred during this month. The sample included nearby earthquakes exhibiting a difference in the arrival of longitudinal (P) and transverse (S) elastic waves of up to 6 seconds (within a radius of $50 \mathrm{~km}$ from the blast area) and having occurred no later than 10 hours after the corresponding rock blast, as well as the volume of the rock mass blasted during the specified period.

The impact of mining operations carried out in the Neryungrinsky coal mine on the induced seismicity in the nearby area $\left(1^{0} \times 1^{0}\right)$ was estimated by calculating the released energy on an annual basis (Fig. 1). The average energy value for the 1979-2005 period is shown to range from $\mathrm{K}=9$ to $\mathrm{K}=10\{\mathrm{~J}\}$. The $1989-1990$ period is characterized by a peak in the released energy of higher than $\mathrm{K}=11\{\mathrm{~J}\}$. It should be noted that it is during this period that a great number of uncovering and mining operations were being performed in the Neryungrinsky coal mine. It can therefore be concluded that drilling and blasting operations do have an impact on the overall energy balance of the seismotectonic process [14].

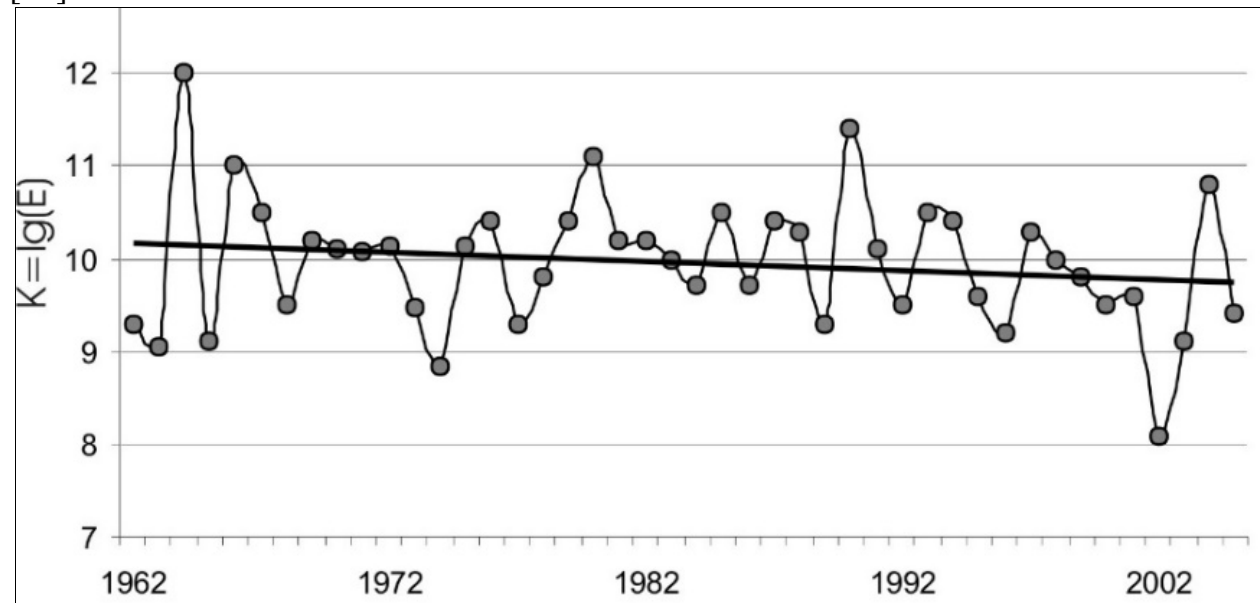

Fig. 1. Distribution of average annual energies from earthquakes within a radius of $50 \mathrm{~km}$ from blasting operations

The average energy value for the $1962-2005$ period ranges from $\mathrm{E}=10^{10.2}$ to $\mathrm{E}=10^{9.8}$ $\{\mathrm{J}\}$ following a linear function. However, the total energy released yearly was higher for the periods preceding mining operations, which indicates a downward redistribution of earthquake energy (Figure 1). In general, this graph has the form of a linear function with a constant slope.

Therefore, active anthropogenic impact on the geological environment causes a seismic response manifested in the form of a change in the level of seismic activity. Under the influence of explosions, both the number of seismic events and the average level of released energy change. It is established that the centres of technogenic earthquakes are either confined to the points of explosion, or located north-west along the tectonic structures crossing the quarry field.

The patterns of induced and natural seismicity in the area of open mining were established by analysing data obtained from 5-year monitoring observations carried out at the Neryungri seismic station (NSS). Over the 2002-2007 period, its specialists registered over 500 explosions manifested in the form of seismic events, on the average, of the $6^{\text {th }}$ energy class. 


\section{Results and discussion}

According to the monitoring data obtained for the 2002-2007 period, 103 out of 135 (the total number of 211) earthquake cases registered in the nearby area (165 in the degree square) occurred within one day after blasts, with 46 events being registered in the vicinity of the technological platform. The technogenic impact on the environment was transformed into an independent local seismic process. In other words, under the action of rock mass blasts, a local stream of seismic events not correlating with the moments of the blasts was initiated. The spatial distribution of the explosions and earthquakes is shown in Fig. 2.

This means that either a new active tectonic structure appeared, to which 165 out of 211 earthquakes $(78 \%)$ having occurred within a radius of $50 \mathrm{~km}$ from the Neryungri coal mine can be referred, or a local section of the Ammunakta-Muastakhsky and NizhneNeryungrinsky active faults became activated. In other words, the seismic process initiated by blasting works, became stationary on a local level. Thus, low-energy impulse loads on the geological environment led to the spatial redistribution of the foci of low-energy $(\mathrm{K}<7)$ earthquakes (Fig.2).

The obtained results show that active impact on the environment causes a seismic response manifested in the form of a correlated change in seismic activity. Under the influence of energy loads on the geological environment, the near-surface layers of the Earth's crust were activated in a zone experiencing the dynamic influence of AmmunaktaMuastakhsky and Nizhne-Neryungrinsky active faults.

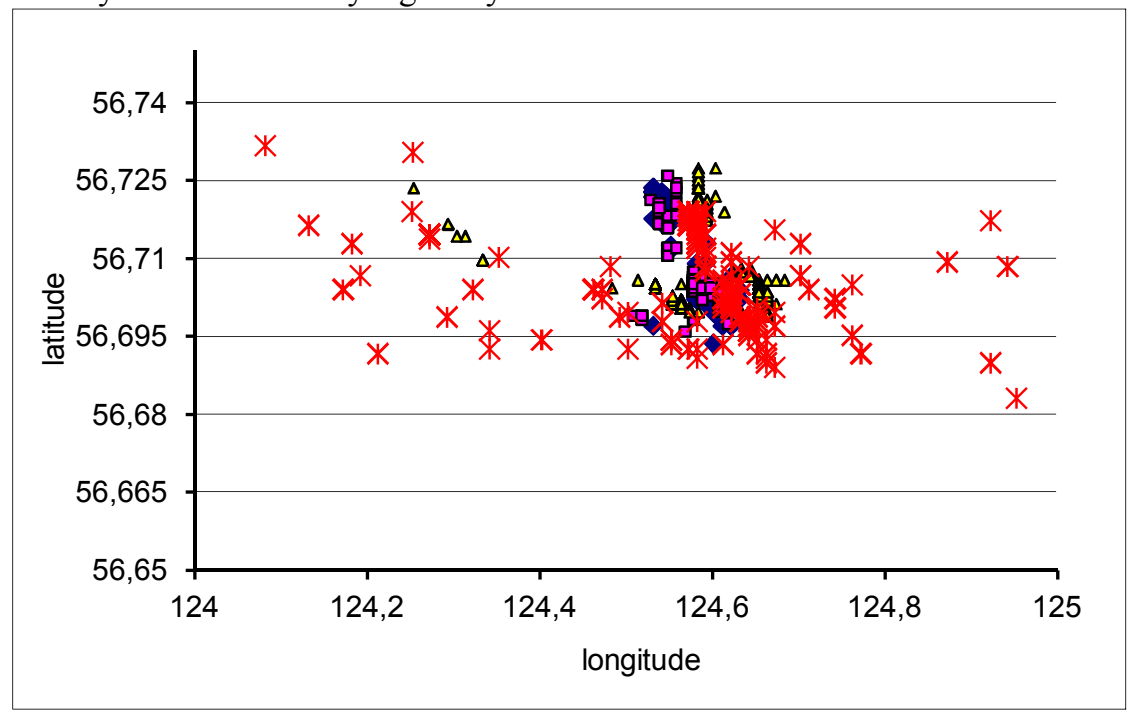

Fig. 2. Spatial distribution of explosion points and weak $(K<7)$ earthquake epicentres near the technological platform of the Neryungri coal mine: $ж$ - earthquakes $2002-2007$;

- 2004 - $2005 \quad 2006$ - explosions

The geodynamic development of seismogenic faults is known to result from the movement of their sides [18] in the form of mutual "slippage". Seismic events are manifested provided the aforementioned form of deformation is impossible or difficult to develop, in other words, when stress-state zones in the Earth's crust arise. Therefore, in our opinion, the shaking impact of blasting can be considered as a factor contributing to the predominance of aseismic forms of fault motion in the form of smooth slippage of their sides. Consequently, the impact of blasting can not only activate faults around the mining area, but also have an unloading effect on the foci of seismic hazard forming in the interior, i.e. the redistribution of earthquake energy towards reduction of their energy class. 
Since 2003, open coal mining works have been actively performed in small quarries. By 2007, the total energy impact of these enterprises on the geological environment exceeded that produced by the Neryungri coal mine by $10 \%$ [14]. However, the launch of the Vostochnaya Denisovka mine in 2013 led to a sharp increase in the number of technogenic earthquakes, with this number reaching 30 cases during 10 hours after a blast. Instrumental observations have shown that the epicentres of the earthquakes initiated by the explosions produced in the Vostochnaya Denisovka mine do not geographically coincide with the epicentres of the earthquakes initiated by the explosions in the Neryungrinsky coal mine. Using the results of explosion and local earthquake monitoring, we have identified the focus of a new earthquake (a square highlighted in grey) related to the explosions in the Vostochnaya Denisovka coal mine (Fig. 3). This site was analysed in detail taking into account its tectonic structure. It is established that the induced seismicity in this site was associated with the tectonic structures stretching from the North to the South and crossing the quarry field of the Vostochnaya Denisovka coal mine.

Therefore, the impact of rock blasts on the geological environment of the-newly launched coal mine caused a seismic response in the form of changed seismic activity, activating tectonic structures in the area of blasting operations in the Vostochnaya Denisovka coal mine that had not manifested themselves before. Under the influence of rock blasts, the number of seismic events changes. The spatial distribution of the epicentres of induced seismicity initiated by the explosions produced in the Vostochnaya Denisovka coal mine is presented in Fig. 4.

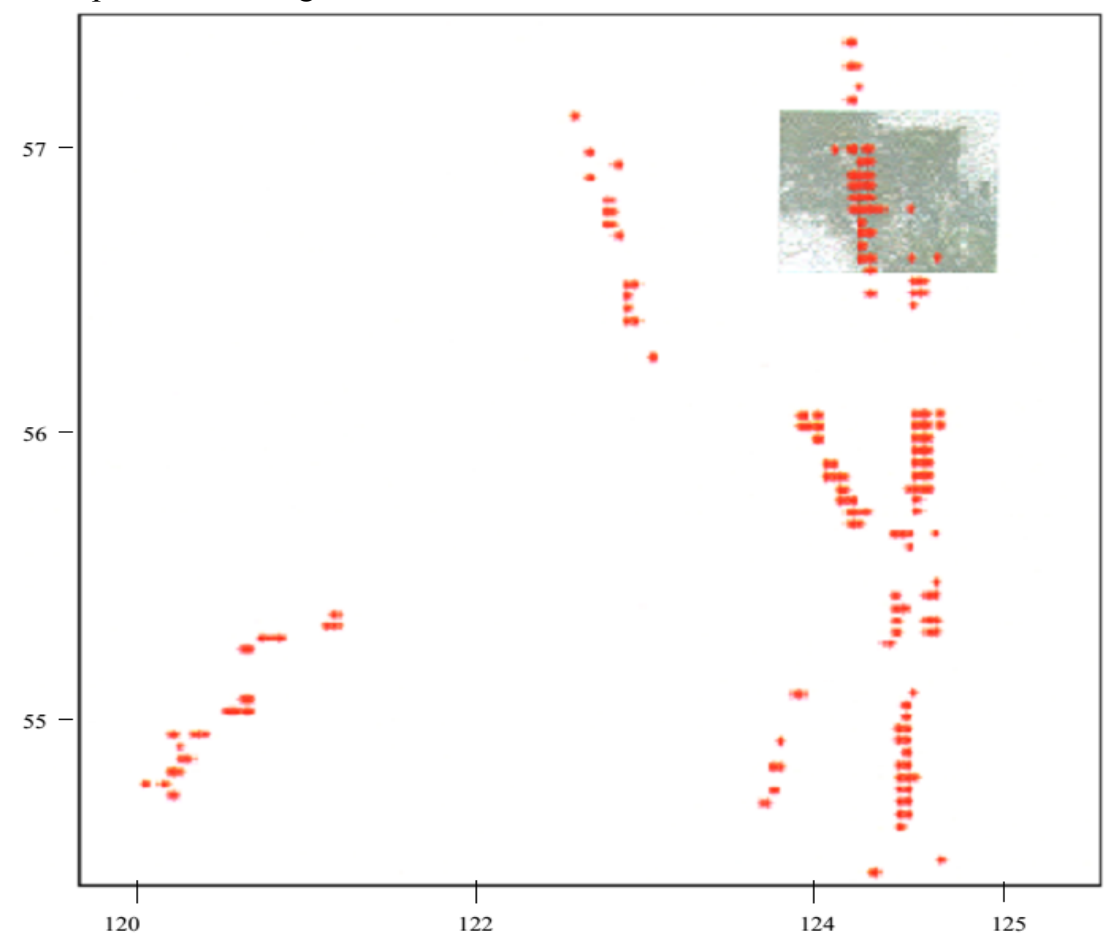

Fig. 3. Epicentres of local earthquakes registered in 2012-2013: * - seismic events 


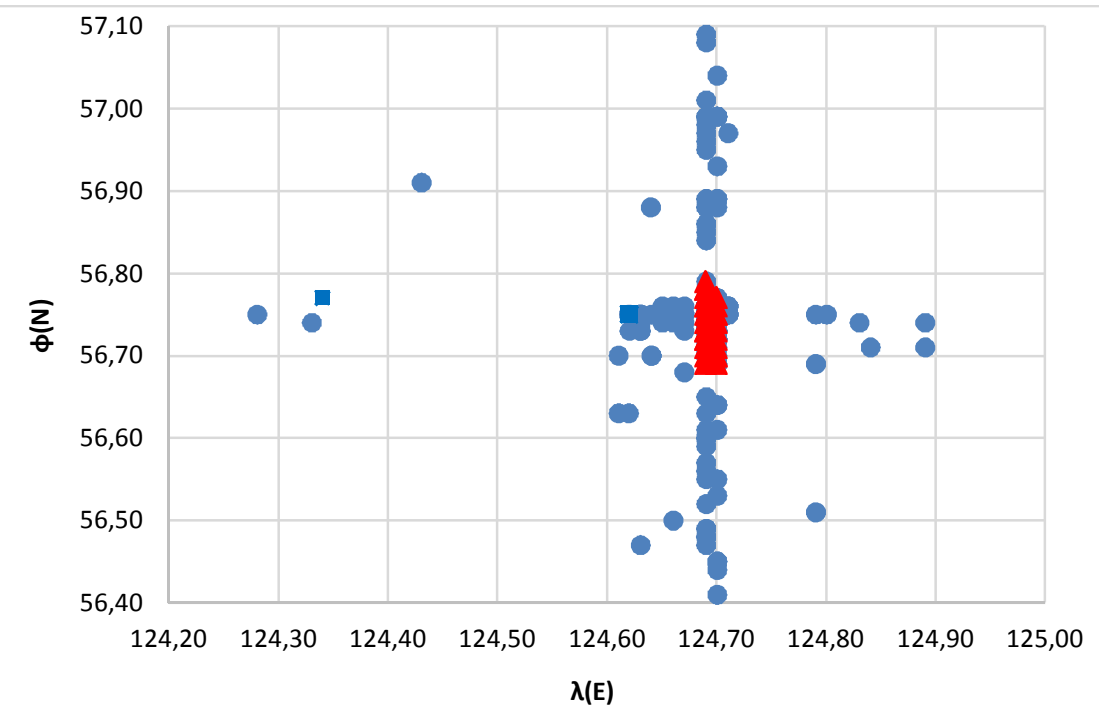

Fig. 4. Spatial distribution of the epicentres of blasts in the Vostochnaya Denisovka coal mine and the epicentres of technogenic earthquakes: $\boldsymbol{\Delta}$ - explosions; $\bullet$ - earthquakes

The results of seismological monitoring carried out in 2013 have shown that the epicentres of technogenic earthquakes were confined to the rock blocks being exploded or to the tectonic structures crossing the quarry field from the North to the South. It should be noted that the maximal activation of the induced seismicity was related to the explosions on the eastern flank of the mining front, where the tectonic structure had been uncovered by mining operations.

\section{Conclusions}

It can be concluded that an increase in the technogenic load on the geological and geophysical environment causes irreversible phenomena in the seismic process. Under the influence of rock blasts, the number of seismic events along with the average level of released energy alter. Active impact on the geological environment causes a seismic response manifested in the form of technogenic earthquakes, activating seismic generating structures located in the area of industrial blasts.

The seismic process initiated by blasting works acquires a stationary character at the local level; low-energy impulse loads on the geological environment lead to a spatial redistribution of the foci of low-energy $(K<7)$ earthquakes. Blasting works can not only activate faults around the mining area, but also have an unloading effect on the foci of seismic hazard forming in the interior, i.e. the redistribution of earthquake energy towards reduction in their energy class.

\section{References}

1. L. Imaeva, B. Koz'min, V. Imaev, N Grib, S Ashurkov. Journal of Seismology, 21(2), 385 (2017).

2. A. Gamburtsev, N. Gamburtseva, I. Galkin, R. Nikolaeva, O. Oleinik. The induced processes in the lithosphere: induced seismicity, 16 (1973).

3. Nikolaev A. Bulletin of the Russian Academy of Sciences, 63(2), 113 (1993).

4. A. Nikolaev, I. Galkin. Induced seismicity (1973). 
5. A. Nikolaev, G. Vereshchagina. DAN SSSR, 319(2), 333, (1991).

6. Wong I.G. Informing Risk Management and Mitigation (2015).

7. N. Grib, A. Syasko, V. Imaev, G. Grib, A. Kachaev. Seismic Instruments, 54(1), 101 (2018).

8. Yu. Kuzmin, V. Zhukov. Gornaya kniga (2012).

9. I. Ananyin. Problems of engineering seismology, 29, 119 (1988).

10. A. Antsiferov, A. Mayboroda, A. Savchenko, V. Tumanov. Transactions of UkrNDMI NAN Ukraine, 11, 251 (2012).

11. W. Ellsworth. Injection-Induced Earthquakes. Science, 341(6142), 142 (2013).

12. N. Melnikov. Technogenic seismicity in mining operations: models of foci, prognosis, prophylaxis. Proceedings of International Meeting: in 2 parts, 2 (2004).

13. A. Emanov, A. Emanov, E. Leskov, A. Fateev, A. Semin. Physical mesomechanics, 12(1), 37 (2009).

14. G. Grib, N. Grib. Izvestiya of the Samara Russian Academy of Sciences scientific center, 16(1(3)), 636 (2014).

15. A. Emanov, A. Emanov, A. Fateev V. et al. Earthquakes in Russia in 2012, 104 (2014).

16. V. Sychev. Published summary of Candidate of Physics-Mathematical Sciences (2008).

17. K. Woodward, J. Wesseloo. Journal of the Southern African Institute of Mining and Metallurgy, 115(11), 1044 (2015).

18. N. Grib, G. Grib, V. Imaev, M. Tereshchenko. Mining Journal, 10, 31 (2016). 